\title{
Association of Anti-apoptotic Mechanism Due to House Dust Mite in Neutrophils with Protein Synthesis and Bad
}

\author{
In Sik Kim ${ }^{1,2}$ and Ji-Sook Lee $\mathrm{C}^{3, \dagger}$ \\ ${ }^{I}$ Department of Biomedical Laboratory Science, School of Medicine, Eulji University, Daejeon 34824, Korea \\ ${ }^{2}$ Department of Senior Healthcare, BK21 plus Program, Graduate School, Eulji University, Daejeon 34824, Korea \\ ${ }^{3}$ Department of Clinical Laboratory Science, Wonkwang Health Science University, Iksan 54538, Korea
}

House dust mite is an essential allergen in the pathogenesis of allergic diseases. Abnormal regulation of neutrophil apoptosis is an important pathogenic process in allergic diseases. In the present study, we investigated the effects of house dust mites on spontaneous apoptosis of neutrophils and its associated mechanisms. Extract of Dermatophagoides pteronissinus (DP) inhibited neutrophil apoptosis in a time-dependent manner. Cycloheximide (CHX), an inhibitor of translation, increased apoptosis of DP-treated neutrophils as well as control cells. The pro-apoptotic effect of CHX was blocked by DP in neutrophils. In addition, DP increased the phosphorylation of Bad in a time-dependent manner, indicating that it exerted an inhibitory effect on the function of Bad. These results suggest that DP has anti-apoptotic effects of neutrophils and may regulate protein synthesis and activation of Bad. Moreover, these findings may shed light on elucidation of allergy pathogenesis due to house dust mites.

Key Words: House dust mite, Neutrophil apoptosis, Translation process, Bad

\section{INTRODUCTION}

Allergic diseases, which are characterized by inflammation and microbial or viral infection, include asthma, allergic rhinitis, atopic dermatitis, and allergic conjunctivitis (Leung and Guttman-Yassky, 2014; Linneberg et al., 2016; Thomas, 2016). House dust mite allergens primarily consist of Dermatophagoides pteronyssinus (DP) and Dermatophagoides farina (DF), which are the major allergens affecting allergy pathogenesis (Milián and Diaz, 2004; Kim et al., 2013; Kang et al., 2014). Infiltration of neutrophils into inflamed tissue is an essential process of inflammatory responses. Dysregulation of neutrophil apoptosis increases the survival of neutrophils, which exist in the tissues for a long time. The sustained neutrophils continue to induce inflammatory response, ultimately aggravating both symptoms and phenotypes of allergic diseases (Bascom et al., 1988; Monteseirín, 2009; Lee et al., 2014; Lee et al., 2016).

\section{MATERIALS AND METHODS}

This study was approved by the Institutional Review Board of Eulji University for normal volunteers. All participants in the study gave their written informed consent. Human neutrophils were separated from the heparinized peripheral blood of healthy volunteers using Ficoll-Hypaque gradient centrifugation and a CD16 microbeads magnetic cell sorting

*Received: November 16, 2016 / Revised: December 12, 2016 / Accepted: December 12, 2016

$\dagger$ Corresponding author: Ji-Sook Lee. Department of Clinical Laboratory Science, Wonkwang Health Science University, Iksan 54538, Korea. Tel: +82-63-840-1216, Fax: +82-63-840-1219, e-mail: jslee1216@wu.ac.kr

(C) The Korean Society for Biomedical Laboratory Sciences. All rights reserved.

(c) This is an Open Access article distributed under the terms of the Creative Commons Attribution Non-Commercial License (http://creativecommons.org/licenses/by-nc/3.0/) which permits unrestricted non-commercial use, distribution, and reproduction in any medium, provided the original work is properly cited. 
A

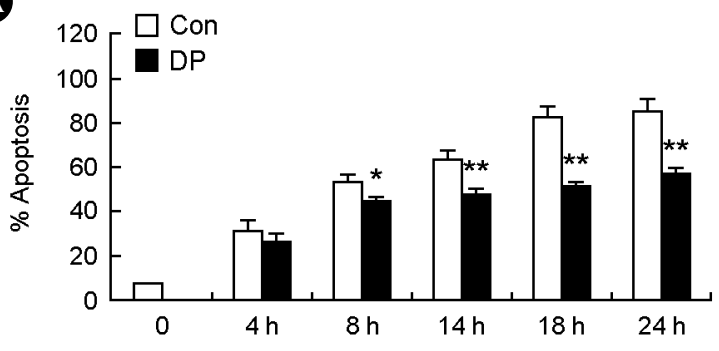

B
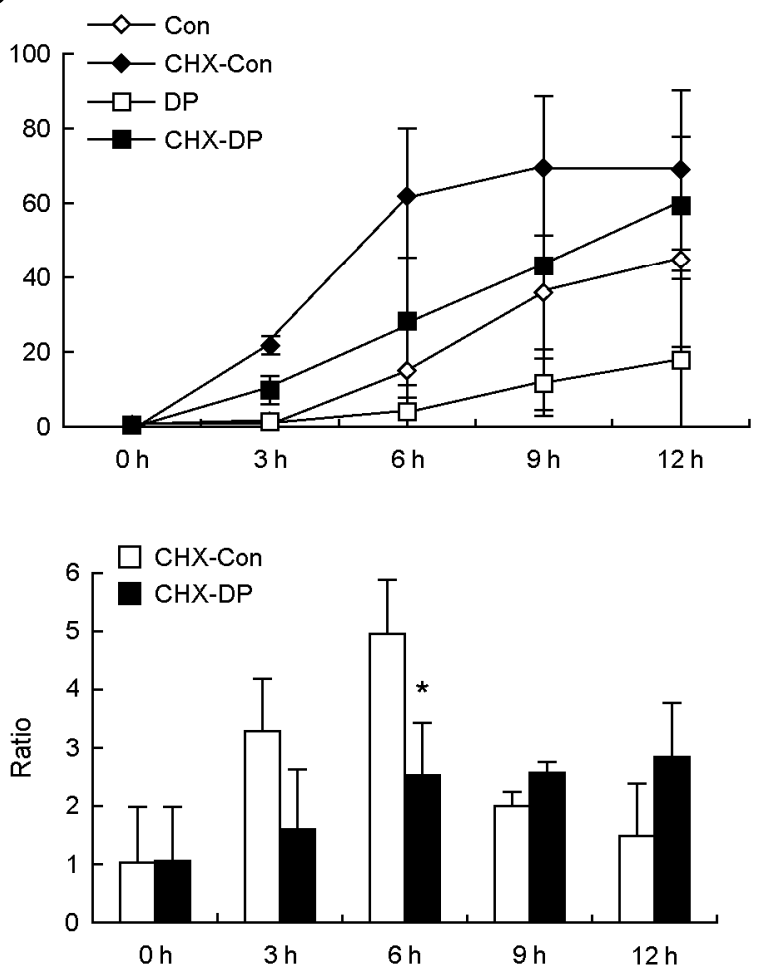

Fig. 1. Anti-apoptotic effects of DP on neutrophils is associated with protein synthesis. Normal neutrophils were isolated from the peripheral blood of normal subjects $(3<\mathrm{n}<5)$. The neutrophils were incubated with and without $10 \mu \mathrm{g} / \mathrm{mL}$ of DP (A) or $/$ and $10 \mu \mathrm{g} / \mathrm{mL}$ cycloheximide (CHX) (B) for the indicated time. Apoptosis was analyzed by measuring the binding of annexin V-FITC and PI. Data are expressed as the means \pm SD and are presented relative to the control, which was set at $100 \%$. $* P<0.05$ and ${ }^{* *} P<0.01$ indicate a significant difference between the untreated control and DP-treated groups. Lower panel of $\mathrm{B}$ represents the ratio of control neutrophil and DP-treated neutrophil apoptosis due to CHX. These results were derived from data of upper panel of $\mathrm{B}$.

kit (Miltenyi Biotec, Bergisch Gladbach, Germany). Erythrocytes in the cells were removed by washing with hypotonic lysis, after which the cells were resuspended at $3 \times 10^{6} / \mathrm{mL}$ in RPMI 1640 medium with $10 \%$ FBS. An annexin Vfluorescein isothiocyanate (FITC) apoptosis detection kit (BD Biosciences, San Diego, CA, USA) was used to evaluate neutrophil apoptosis. Isolated neutrophils were incubated with an FITC-labeled annexin V and propidium iodide (PI) for $15 \mathrm{~min}$ at room temperature. Apoptotic neutrophils were analyzed using a FACSCalibur with the CellQuest software (BD bioscience) and were determined as the percentage of cells showing annexin $\mathrm{V}+/ \mathrm{PI}-$ and annexin $\mathrm{V}+/ \mathrm{PI}+$. After being treated with DP in a time-dependent manner, neutrophils were collected and lysed in total lysis buffer. The homogenate was centrifuged at $12,000 \mathrm{~g}$ for $15 \mathrm{~min}$ at $4{ }^{\circ} \mathrm{C}$, after which the supernatant was collected as total lysate. Next, $50 \mu \mathrm{g}$ of protein per lane were loaded into the well and separated by SDS-polyacrylamide gel electrophoresis (SDS-PAGE), after which they were transferred to membranes, incubated with anti-phospho-Bad antibodies and developed using the enhanced chemiluminescence detection system (Amersham Biosciences, NJ, USA). The same blot was stripped and reprobed with anti-ERK2 antibodies for use as an internal control.

\section{RESULTS AND DISCUSSION}

Here, we examined whether DP affects alterations in neutrophil apoptosis for the first time. DP suppressed constitutive apoptosis of neutrophils isolated from healthy subjects in a time-dependent manner (Fig. 1A). Strong inhibition of neutrophil apoptosis was observed at $18 \mathrm{~h}$ and $24 \mathrm{~h}$ after DP treatment. These results are similar to the effects of DP on neutrophil apoptosis in our previous study (Kim et al., 2015). Since protein synthesis is an important regulatory mechanism of apoptosis, we treated neutrophils with cycloheximide (CHX), an inhibitor of protein translation, to investigate alterations in the translation process and apoptosis due to DP (Scheel-Toellner et al., 2004). CHX increased neutrophil apoptosis in a time-dependent manner and recovered the inhibition of neutrophil apoptosis induced by DP (Fig. 1B upper panel). Because CHX enhanced control neutrophil apoptosis, we examined the ratio of control neutrophils and DP-treated neutrophil apoptosis due to CHX. Apoptosis of control neutrophils due to CHX was higher 

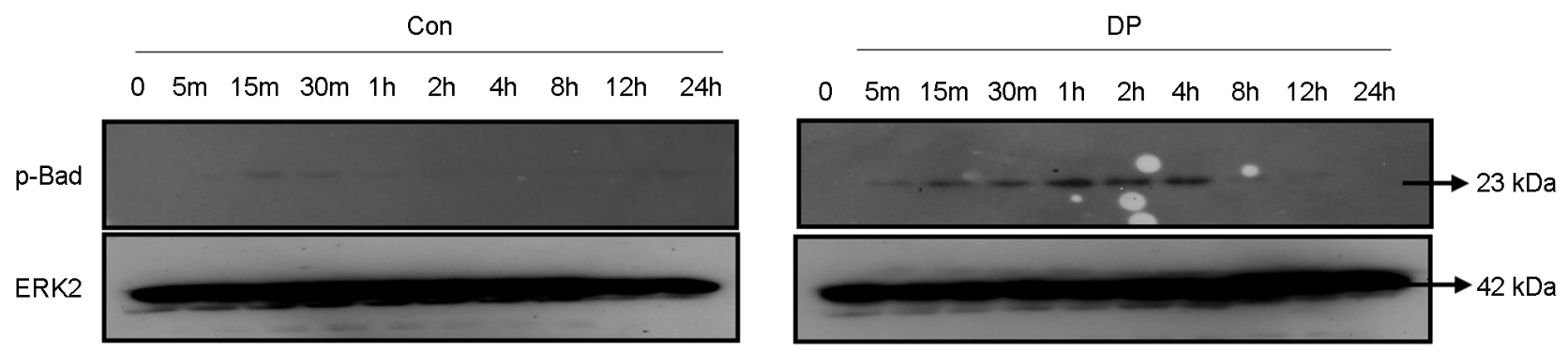

Fig. 2. DP induces the phosphorylation of Bad in neutrophils. Normal neutrophils were treated with and without $10 \mu \mathrm{g} / \mathrm{mL}$ of $\mathrm{DP}$ for the indicated time. Phosphorylation of Bad in the lysates was detected by Western blotting. The membrane was stripped and reprobed with anti-ERK2 antibodies as an internal control.

than that of DP-treated neutrophils at $3 \mathrm{~h}$ and $6 \mathrm{~h}$ (Fig. 1B lower panel). The results presented herein provide important information regarding the role of DP in neutrophil apoptosis. First, the anti-apoptotic effect of DP is associated with the translation process. When we considered the short experimental time, DP may increase the stability of mRNA, which is involved in survival or anti-apoptosis. Second, DP inhibits neutrophil apoptosis induced by CHX in aspects of CHX treatment, as well as spontaneous neutrophil apoptosis. Taken together, DP regulated the translation process, which is related to neutrophil apoptosis. Bad is a protein belonging to the Bcl-2 family that induces apoptosis by heterodimerizing anti-apoptotic proteins such as Bcl-2 or Bcl-xL (Bergmann, 2002). We next investigated the involvement of Bad in the anti-apoptotic effects of DP. DP induced phosphorylation of Bad in a time-dependent manner (Fig. 2). Phosphorylation of Bad was achieved by a variety of kinases including cAMP-dependent protein kinase (PKA) and cyclin-dependent kinase 1 (CDK1) (Virdee et al., 2000; Konishhi et al., 2002). The phosphorylation of Bad induces the sequestration of Bad in the cytosol by binding to 14-4-3. Future studies are needed to elucidate the exact mechanism of DP associated with Bad. These results may help us understand the regulation of spontaneous neutrophil apoptosis due to house dust mites.

\section{Acknowledgement}

This paper was supported by Wonkwang Health Science University in 2016.

\section{Conflict of interest}

The authors have no financial conflicts of interest.

\section{REFERENCES}

Bascom R, Pipkorn U, Lichtenstein LM, Naclerio RM. The influx of inflammatory cells into nasal washings during the late response to antigen challenge: effect of steroid pretreatment. Am Rev Respir Dis. 1988. 138: 406-412.

Bergmann A. Survival signaling goes BAD. Developmental Cell. 2002. 3: 607-608.

Kang BK, Kim MA, Park SH, Lee EJ, Kim JS, Kim EJ, Baek SY, Kim IS. The house dust mite allergen, Dermatophagoides pteronyssinus regulates the constitutive apoptosis and cytokine secretion of human eosinophils. Biomed Sci Lett. 2014. 20: $39-42$.

Kim DH, Choi E, Lee JS, Lee NR, Baek SY, Gu A, Kim DH, Kim IS. House dust mite allergen regulates constitutive apoptosis of normal and asthmatic neutrophils via Toll-like receptor 4 . PLoS One. 2015. 11: 3995-4001.

Kim IS, Kim EH, Kim DH, Kim JS, Lee JS. Effect of house dust mite and CCL2 on S100A8 and S100A9 expression in human monocytes. Biomed Sci Lett. 2013. 19: 344-347.

Konishi Y, Lehtinen M, Donovan N, Bonni A. Cdc2 phosphorylation of BAD links the cell cycle to the cell death machinery. Mol Cell. 2002. 9: 1005-1016.

Lee JS, Kim IS. Suppressive effect of arazyme on neutrophil apoptosis in normal and allergic subjects. Biomed Sci Lett. 2014. 20: $244-249$

Lee NR, Baek SY, Gu A, Kim da H, Kim SY, Lee JS, Kim IS. House dust mite allergen suppresses neutrophil apoptosis by 
cytokine release via PAR2 in normal and allergic lymphocytes. Immunol Res. 2016. 64: 123-132.

Leung DY, Guttman-Yassky E. Deciphering the complexities of atopic dermatitis: shifting paradigms in treatment approaches. J Allergy Clin Immunol. 2014. 134: 769-779.

Linneberg A, Dam Petersen K, Hahn-Pedersen J, Hammerby E, Serup-Hansen N, Boxall N. Burden of allergic respiratory disease: a systematic review. Clin Mol Allergy. 2016. 14:12.

Milián E, Diaz AM. Allergy to House Dust Mites and Asthma. P R Health Sci J. 2004. 23: 47-57.

Monteseirín J. Neutrophils and asthma. J Investig Allergol Clin
Immunol. 2009. 19: 340-354.

Scheel-Toellner D, Wang KQ, Webb PR, Wong SH, Craddock R, Assi LK, Salmon M, Lord JM. Early events in spontaneous neutrophil apoptosis. Biochem Soc Trans. 2004. 32: 461-464.

Thomas WR. House dust mite allergens: New Discoveries and Relevance to the Allergic Patient. Curr Allergy Asthma Rep. 2016. 16: 69.

Virdee K, Parone PA, Tolkovsky AM. Phosphorylation of the proapoptotic protein BAD on serine 155, a novel site, contributes to cell survival. Current Biology. 2000. 10: 1151-1154. 